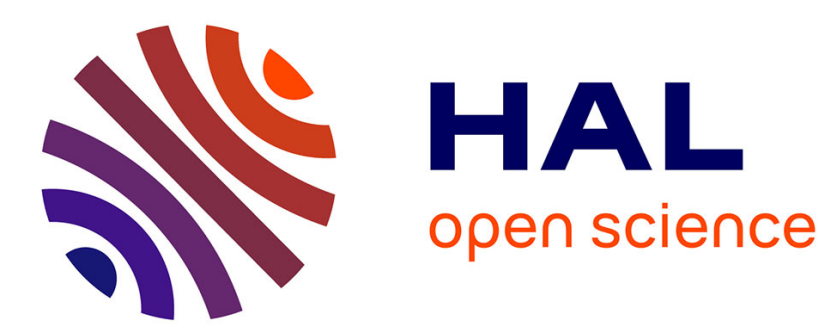

\title{
Surface modification of zinc oxide nanoparticles by aminopropyltriethoxysilane
}

Fabien Grasset, N. Saito, D. Li, D. Park, I. Sakaguchi, N. Ohashi, H. Haneda, T. Roisnel, Stéphane Mornet, Etienne Duguet

\section{- To cite this version:}

Fabien Grasset, N. Saito, D. Li, D. Park, I. Sakaguchi, et al.. Surface modification of zinc oxide nanoparticles by aminopropyltriethoxysilane. Journal of Alloys and Compounds, 2003, 360 (1-2), pp.298-311. 10.1016/S0925-8388(03)00371-2 . hal-00173186

\section{HAL Id: hal-00173186 \\ https://hal.science/hal-00173186}

Submitted on 4 Dec 2020

HAL is a multi-disciplinary open access archive for the deposit and dissemination of scientific research documents, whether they are published or not. The documents may come from teaching and research institutions in France or abroad, or from public or private research centers.
L'archive ouverte pluridisciplinaire HAL, est destinée au dépôt et à la diffusion de documents scientifiques de niveau recherche, publiés ou non, émanant des établissements d'enseignement et de recherche français ou étrangers, des laboratoires publics ou privés. 


\title{
Surface Modification of Zinc Oxide NanoParticles by Aminopropyltriethoxysilane
}

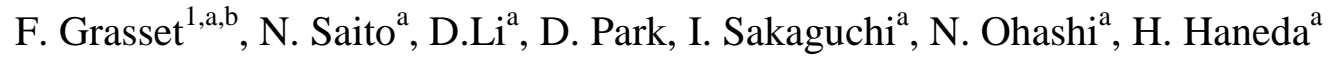 \\ ${ }^{a}$ National Institute for Materials Science-Advanced Materials Laboratory, NIMS-AML, \\ Namiki 1-1, Tsukuba, Ibaraki, 305-0044, Japan. \\ bLaboratoire "verres et céramiques", UMR CNRS 6512, Institut de Chimie de Rennes, \\ Université de Rennes 1, F-35042 Rennes Cedex, France. \\ T. Roisnel \\ Laboratoire de Chimie du Solide et Inorganique Moléculaire, UMR CNRS 6511, Institut de \\ Chimie de Rennes, Université de Rennes 1, F-35042 Rennes Cedex, France \\ S. Mornet, E. Duguet \\ Institut de Chimie de la Matière Condensée de Bordeaux, ICMCB-CNRS, Université \\ Bordeaux-1, 87 avenue du Dr Albert Schweitzer, F-33608 Pessac Cedex, France
}

Abstract: Commercial zinc oxide nanoparticles (20-30nm) were coated by aminopropyltriethoxysilane (APTES) under varying environments. Three different processes, acidic, basic and toluene were used. The effects of coating conditions (acidic, basic and toluene) on the grafting, structural and optical properties of these nanoparticles were studied. In the three cases, it was possible to control the coating and according to X-ray diffraction, BET, TEM and SEM results, it is clear that the APTES coating plays a role of growth inhibitor even at $800^{\circ} \mathrm{C}$. From diffuse reflectance measurements, one can notice that the grafting process did not modify the transmittance spectra of $\mathrm{ZnO}$.

Keywords: A: Nanostructure, Surface and interfaces, B: Chemical synthesis, C: X-ray diffraction

1'grasset@univ-rennes1.fr, Tel: 33 (0)2 232365 40, Fax: 33 (0)2 23235683 
Zinc oxide $(\mathrm{ZnO})$, one of the II-VI compound semiconductor ${ }^{1}$, is an important material for applications such as chemical sensors ${ }^{2}$, varistors ${ }^{3}$, thin film photovoltaic solar cells ${ }^{4,5}$, piezoelectric and luminescent devices ${ }^{6}$ catalysis $^{7}$ and cosmetic materials ${ }^{8-10}$.

Since it was found that high quality epitaxial $\mathrm{ZnO}$ thin film displays excitonic ultraviolet laser action at room temperature (RT) (band gap energy of $3.37 \mathrm{eV})^{11}$, research on thin film zinc oxide materials has increased enormously during the five past years ${ }^{12-35}$. At the present time zinc oxide is considered as one of the most promising and novel photonic materials for the blue, violet and $\mathrm{UV}$ regions ${ }^{13}$. At the same time, $\mathrm{ZnO}$ submicronic particles offer considerable potential as a starting material for such optical applications ${ }^{36-46}$ and also for other purposes such as varistors ${ }^{47-53}$ and transparent UV-protection (sunscreen formula) ${ }^{8-10}$. About the last mentioned application, in fact, it is well known that oxides like $\mathrm{CeO}_{2}, \mathrm{TiO}_{2}$ and $\mathrm{ZnO}$ with band gap energy and refractive index close to $3 \mathrm{eV}$ and 2-3 have ideal characteristics in a broad-spectrum inorganic sunscreen. Nevertheless, the photocatalytic activity of these three oxides can facilitate the generation of reactive species, which can degrade other organic compounds in the formulation. Recently, it was shown that the oxidation catalytic activity of $\mathrm{CeO}_{2}$ could successfully be decreased by coating with amorphous silica ${ }^{54}$ but coating with amorphous silica resulted in decreasing UV-shielding effect. In this study, commercial $\mathrm{ZnO}$ nanoparticles were grafted by aminopropyltriethoxysilane (APTES) in various conditions in order to compare the properties of coated and non-coated powders. Three different conditions were used to graft APTES onto the zinc oxide surface. The powders before and after grafting process have been annealed at $800^{\circ} \mathrm{C}$ and studied by X-ray diffraction (XRD). Transmission electron microscopy (TEM), scanning electron microscopy (SEM) and specific surface area measurements were performed 
to control the effect of coating and sintering on the growth of $\mathrm{ZnO}$ nanoparticles. The optical transmittance spectrum of the coated and non-coated powders are compared.

\section{Experimental section}

\subsection{Products}

Ultrafine $\mathrm{ZnO}$ powder (Nanofine P2) was provided by Sakai Chemical Industry. APTES, anhydrous toluene, nitric acid and tetramethylammonium hydroxide (25\% aqueous solution) (TMOH) were provided by Aldrich.

The grafted APTES in acidic condition (or basic condition) was prepared following this process: $1.5 \mathrm{~g}$ of commercial zinc oxide was dispersed into distilled water $(50 \mathrm{ml}, \mathrm{pH}=$ 6.8 7.2), the starting $\mathrm{pH}$ was adjusted to 6.5 with $\mathrm{HNO}_{3}$ solution $(2 \mathrm{M})$ (or 10.8 with $\mathrm{TMOH}$ ). The suspension was stirred for a further $1 \mathrm{~h}$ and $1 \mathrm{ml}$ of APTES was added. After addition of APTES, because of the basic property of the amino group, the $\mathrm{pH}$ was increased to 9.7 and after few minutes was stabilized to 8.9 9.2 for the acid condition whereas for the basic starting $\mathrm{pH}$ (10.8) was decreased and stabilized to 10.4 10.6. The reaction mixture was stirred for a further $24 \mathrm{~h}$ then excess APTES was removed by filtration and washing with alcohol and acetone. The powder was dried at $60^{\circ} \mathrm{C}$ under vacuum.

The grafted APTES in toluene condition was performed with $2 \mathrm{~g}$ of commercial zinc oxide. The powder was dried at $110^{\circ} \mathrm{C}$ under vacuum for $2 \mathrm{~h}$ and was dispersed into anhydrous toluene $(200 \mathrm{ml})$ under argon flow. The suspension was stirred for a further $1 \mathrm{~h}$ and $1 \mathrm{ml}$ of APTES was added slowly under argon flow. The reaction mixture was refluxed under an argon flow for further 15h, excess APTES was removed by filtration and washing with fresh toluene and dried under vacuum at $110^{\circ} \mathrm{C}$ for $2 \mathrm{~h}$ to remove toluene.

In all cases, subsequently one part of the non-grafted and grafted powder was heated at $800^{\circ} \mathrm{C}$ in air for 8 hours. 


\subsection{X-ray powder diffraction}

X-ray diffraction data were recorded at room temperature on a Philips PW 3020 using Bragg-Brentano geometry with $\mathrm{CuK \alpha}$ radiation $(40 \mathrm{kV}, 30 \mathrm{~mA})$ and secondary monochromator. The average apparent crystallite size $\left(\varepsilon_{\beta}\right)$ is evaluated from a whole diffraction pattern profile analysis, using last developments implemented in the Fullprof program (version 2.0 Nov 2001, LLB, Juan Rodriguez-Carvajal). Describing instrumental and intrinsic profiles by normalized Voigt function (convolution of gaussian and lorentzian functions), size and strain effects can be separated from a whole profile pattern analysis based on the different angular dependence of the gaussian and lorentzian Full-Width-at-HalfMaximum $\left(\mathrm{H}_{\mathrm{G}}\right.$ and $\mathrm{H}_{\mathrm{L}}$ respectively) following these equations

$$
\begin{gathered}
\mathrm{H}_{\mathrm{G}}^{2}=\left(\mathrm{U}_{\text {strain } \_ \text {iso }}+(1-\xi) \mathrm{D}_{\text {strain_aniso }}^{2}\right) \operatorname{tg}^{2} \theta+\frac{\mathrm{G}_{\text {size } \_ \text {iso }}}{\cos ^{2} \theta} \\
\mathrm{HL}=\left(\mathrm{X}_{\text {strain } \_ \text {iso }}+\xi \mathrm{D} \text { strain_aniso }\right) \operatorname{tg} \theta+\frac{\text { Ysize_iso }+ \text { Fsize_aniso }}{\cos \theta}
\end{gathered}
$$

where $\mathrm{U}, \mathrm{X}, \xi, \mathrm{G}$ and $\mathrm{Y}$ are refinable parameters, and $\mathrm{D}$ and $\mathrm{F}$ are analytical functions, depending on a set of additionable refinable parameters, to model the hkl-dependent broadening due to strain and size effects respectively. "Perfect" $\mathrm{Y}_{2} \mathrm{O}_{3}$ powder was used as standard to determine the Instrumental Resolution Function (IRF) of our diffractometer. Observed (hkl) dependent line broadening was modeled by different anisotropic sizes models built into Fullprof, which correspond to particular sets of reflections that are affected by broadening. Refinement of $\operatorname{tg} \theta$ dependent isotropic strain parameters ( $U$ and $X$ parameter in the previous formula) did not improve significantly the profile fitting and only the anisotropic size broadening effects were refined. The best agreement between observed and calculated profiles were obtained considering that the anisotropic size broadening can be written as a linear combination of spherical harmonics $(\mathrm{SPH})^{56}$. In such a case, anisotropic size is supposed to contribute to the lorentzian component of the total voigt function. The explicit 
formula for the SPH is given in ref 55 and 56. After refinement of the coefficients, the program calculates the apparent size along each reciprocal lattice vectors. The average apparent crystallite size $\left(\varepsilon_{\beta}\right)$ can be related to the true size but only if the crystallite shape is known or assumed. For instance, for a spherical crystallite, the true diameter D is simply derived from $4 / 3\left(\varepsilon_{\beta}\right)$. Moreover, this simple relation is strictly valid for a monodisperse system $^{57}$. The true size could be defined, only in the case of single-domain nanoparticles without amorphous shell, as the size estimated from the transmission electron microscopy (TEM) and/or scanning electron microscopic (SEM) images.

\subsection{Morphological investigation by SEM and TEM}

Scanning electron microscopic photographs by Hitachi S-5000 were taken to examine the morphology of non-grafted and grafted $\mathrm{ZnO}$ powders.

A transmission electron microscope (JEOL-2000 FX electron microscope operating at $200 \mathrm{kV}$ ) was used to study the shape and size of the non grafted and non heated zinc oxide nanoparticles. Samples were prepared by direct deposition of powder dispersed in ethanol on carbon activated $\mathrm{Cu}$-grids.

\subsection{Specific Surface area}

The BET specific surface area of the samples was determined by following the standard $\mathrm{N}_{2}$-adsorption method, using a Micromeritics ASAP-200 instrument. Samples were degassed at $200^{\circ} \mathrm{C}$ or $350^{\circ} \mathrm{C}$ for 2 hours and the $\mathrm{N}_{2}$ adsorption isotherms were determined until $77 \mathrm{~K}$.

\subsection{Chemical analysis}

For titration of zinc and silica, Inductive Coupled Plasma (ICP) atomic emission spectroscopy was performed using a spectrophotometer from Seiko Instruments Inc. SPS 
1700HVR. The resonance wavelengths were $\lambda_{(\mathrm{Zn})}=213.86 \mathrm{~nm}$ and $\lambda_{(\mathrm{Si})}=251.61 \mathrm{~nm}$. The powders were heated in air at $500^{\circ} \mathrm{C}$ for $1 \mathrm{~h}$ before analysis to clean the surface.

\subsection{Optical measurements}

Optical transmittance spectra were recorded with a UV-visible spectrophotometer (JASCO V550 UV/Vis.) using diffuse reflectance process.

\section{Results and discussion}

\subsection{Morphological characteristics}

The diffraction patterns of non-grafted $\mathrm{ZnO}$ nanoparticles before and after heating at $800^{\circ} \mathrm{C}$ in air for 8 hours are shown in Figure 1A and 1B respectively. As expected, annealing induces an increase of the crystallite size leading to more sharp diffraction peaks. The comparison of the X-ray diffraction pattern of grafted zinc oxide nanoparticles before and after heating at $800^{\circ} \mathrm{C}$ in air for 8 hours is presented in Figures $2 \mathrm{~A}, 3 \mathrm{~A}, 4 \mathrm{~A}$, and $2 \mathrm{~B}, 3 \mathrm{~B}, 4 \mathrm{~B}$ respectively. Although in the case of basic process the phase $\mathrm{Zn}_{2} \mathrm{SiO}_{4}$ appears as impurity, after heating at $800^{\circ} \mathrm{C}$, the particles growth is quasi-inhibited, as we expected, by APTES coating with the three processes. In more detail, the crystallite sizes, determined by the XRD line broadening technique using the recent developments of the program Fullprof, are reported in Table 1. A comparison of the diffraction patterns of $\mathrm{ZnO}$ nanoparticles and the well crystalline yttrium oxide used as standard are shown in Figure 5. The observed, calculated and difference X-ray diffraction profiles are shown in Figures 6, 7, 8, 9 and 10. A tentative representation of the shape of the zinc oxide nanoparticles using the program GFourier (J. Gonzalez-Platos and J. Rodriguez-carvajal, ver. 3.10) is given in Figure 11. The shape is represented by GFourier using the apparent size calculated by Fullprof along each of the reciprocal lattice vectors (Table 1). The representation along [110] shows the shape of a "star" whereas the representation along [101] shows a more regular shape. This point will be 
discussed later. After annealing (Figure 7), the non-coated zinc oxide presents no peak broadening (i.e. the apparent particle size is fundamentally up to $100 \mathrm{~nm}$ ), whereas, the crystallite size of the three grafted $\mathrm{ZnO}$ (Figure 8, 9 and 10) is keeping almost in the same range as the primary zinc oxide particle (Figure 6 and Table 1). The value of the specific surface area confirms these points (Table 2). In fact, the specific surface area of the nongrafted zinc oxide nanoparticles is $30 \mathrm{~m}^{2} / \mathrm{g}$. After annealing at $800^{\circ} \mathrm{C}$, this material exhibits a reduced specific surface area $\left(2.5 \mathrm{~m}^{2} / \mathrm{g}\right)$ with 12 -fold decrease as compared to the initial specific surface area (Table 2), which is in accordance with the increase of the crystallite size. For grafted powder by acidic and toluene processes, the value of the specific surface area determinated after annealing is only decreased by $\sim 3.5$-fold as compared to the initial specific surface area (Table 2), which was unchanged after grafting. In the case of the basic process, the specific surface area is decreased immediately after grafting and remains unchanged after annealing. XRD patterns (Figure 3) show that this result is not due to a reaction with $\mathrm{TMOH}$. The decrease of the specific surface area may be attributed to the mechanism of condensation of aminosilane in basic media (see part 3.2).

The TEM images of the non-grafted and non heated zinc oxide are shown in Figure 12. One can notice on Figure 12 that the zinc oxide nanoparticles are polydisperse in size and that the nanoparticles are spherical or hexagonal in shape. The diameter of the zinc oxide particles is in the range of $20-30 \mathrm{~nm}$ and is in a very good agreement with the apparent crystallite size determinated by XRD line broadening technique (Table 1). The calculated shapes shown in Figure 11 cannot completely represent the shape observed by TEM (Figure 12). If we consider that there is not an amorphous shell at the surface of the nanoparticles, this difference could be probably explained by the quality of our data and our model and also by the polydispersity of the size. Nevertheless, if the two calculated shapes could explain the two 
different shapes (hexagonal or spherical) observed by TEM, high quality diffraction data are necessary to improve our model.

The SEM images of the non-grafted and grafted powder before and after heating at $800^{\circ} \mathrm{C}$ under isothermal conditions are displayed in Figures 13 (A, B, C, D, E and F). One can notice in Figure 13B that grain growth is significant for the non-grafted $\mathrm{ZnO}$ after annealing at $800^{\circ} \mathrm{C}$. The zinc oxide crystallite size is considerably increased according to the $\mathrm{X}$-ray data (see Figures 1, 7 and Table 1) and it is probable that several crystallites are aggregated into one grain. Indeed, as shown in Figures 13D and 13F (acidic process and toluene process respectively heated at $800^{\circ} \mathrm{C}$ ), the zinc oxide nanoparticles consist of an assembly of ultrafine particles. The diameter of the zinc oxide particles is in the range of $25-45 \mathrm{~nm}$. This result is in a very good agreement with the apparent crystallite size determinated by XRD line broadening technique (Table 1). One can distinguish in the Figure 13E (basic process) "spherical" nanoparticles but accompanied by an strong aggregation process. It seems that $\mathrm{SiO}_{2}$ interparticle aggregation occurred during sintering, which supports the chemical titration data (Table 1) and the BET measurement (Table 2). The SEM study confirms previous results observed for the zinc oxide particles. The most important feature in Figure 13 is that, for the three grafted powders, the crystallite size is keeping almost unchanged compared to the primary crystallite size. Of course, in the case of basic process, the quantity of APTES seems to be a very important parameter and it should be carefully controlled. This point will be discussed in next section.

Regarding all the results for the three grafted powders after annealing, it is clear that the APTES coating plays a role of growth inhibitor. This point could be related to the studies of Audebrand et al. ${ }^{57}$. In fact, they have shown that the low energy for $\mathrm{ZnO}$ crystallite growth must be associated with a surface diffusion process and not a grain boundary or lattice diffusion process, which would require more energy. The silica coating could play a role of 
diffusion barrier. Generally, aminosilane or derivatives are used to stabilize a cluster solution $^{58}$ or to functionalized inorganic materials ${ }^{59-64}$. In the broad field of oxide modification, silica is the most widely used. The aminosilane-modified silica may be used as such or after a secondary treatment. Vrancken et al. ${ }^{65}$ have already shown that the chemical modification of a silica gel, followed by a controlled thermal treatment, under argon atmosphere, converted the silane layer to a $\mathrm{SiC}$ advanced ceramic coating but the phenomenon of growth inhibition by silane was not discussed. Another interesting point is the homogeneity of coating; Although our results, for instance in the acid process, seem to suggest a homogeneous coating, at this time, we cannot completely assume that the coating is homogenous because we can not detect by transmission electron microscopy any homogeneous surface layer of Si-O-Si.

\subsection{Zinc oxide grafting}

Organic silane compounds useful in our method are silane derivatives having at least one organic radical per molecule attached to silicon by a $\mathrm{Si}-\mathrm{C}$ bond. The organic radical is non-hydrolysable and may possess a functionality that imparts the desired characteristics. Typical of the useful silane are those with functional groups as 3-aminopropyltriethoxysilane (APTES) and its analogues. Nevertheless, in the case of UV sun block, it is convenient not to use silanes that are too sensitive to UV radiation as for instance silane with phenyl groups ${ }^{44}$, ${ }^{66}$. One of the problems is that the adhesion between the silane and the oxide surface could be adsorption or covalent bond. The starting point is oxide surface containing hydroxyl groups to which silane molecules could be chemisorbed or physisorbed. It is well known that many metal oxides will hydrolyze in the presence of water (liquid or atmospheric) to form hydroxide layers at the surface. Water molecules may be both physically and chemically adsorbed onto the surface of the oxide particles. An oxide or hydroxide surface can become charged by reacting with $\mathrm{H}^{+}$or $\mathrm{OH}^{-}$ions due to surface amphoteric reactions depending of the 
zero point of charge (ZPC) of the oxide. The ZPC of zinc oxide found in the literature ranges from 9 to $10^{43,67,68}$. Below the ZPC, hydroxide surfaces adsorb protons to produce positively charged surfaces. Above the isoelelectric point, they lose protons to produce negatively charged surfaces. The following equilibria must be considered (S represents the surface of oxide):

$$
\begin{aligned}
& \equiv \mathrm{S}-\mathrm{OH}_{2}^{+}+\mathrm{OH}-\Leftrightarrow=\mathrm{S}-\mathrm{OH}+\mathrm{H}_{2} \mathrm{O} \\
& \equiv \mathrm{S}-\mathrm{OH}+\mathrm{H}_{2} \mathrm{O} \Leftrightarrow \equiv \mathrm{S}-\mathrm{O}^{-}+\mathrm{H}_{3} \mathrm{O}^{+}
\end{aligned}
$$

The number of these sites and the surface charge of the oxide particles are principally dependent of the $\mathrm{pH}$ of the solution ${ }^{67}$, but the useful $\mathrm{pH}$ range may be limited because of the solubility of oxides and the strong $\mathrm{pH}$ dependence of hydrolysis. When zinc oxide is in contact with water, the surface of the oxide is hydrolyzed and a layer of zinc hydroxide is built up. It is well established that zinc hydroxide is slightly soluble in water, becoming more soluble as the $\mathrm{pH}$ is either lowered or raised. Zinc oxide surface is hydrolyzed again in the reaction of the $\mathrm{OH}^{-}$ions with the surface zinc atoms. Also the generation of surface charge due to amphoteric surface reaction may be described simply, only if $\mathrm{H}^{+}, \mathrm{OH}^{-}$and $\mathrm{M}(\mathrm{OH})_{\mathrm{i}}^{2-\mathrm{i}}$ are present in the solution ${ }^{67,68}$. When the cation can form hydroxyl complexes, other species are included in the surface charge formation, then a large number of hydrolytic processes and a variety of equilibria determine the species in solution. The establishment of a surface charge on the metal oxide in water may occur by two distinct but essentially equivalent mechanisms: (1) the adsorption of protons or hydroxyls onto amphoteric surface site or (2) the formation of hydroxylated metal species in solution which deposit on the solid surfaces. Regarding the literature about water suspension of zinc oxide ${ }^{68}$, the surface hydroxide could be in equilibrium with the solution which contains species that can be represented by $\mathrm{Zn}^{2+}, \mathrm{Zn}(\mathrm{OH})^{+}, \mathrm{Zn}(\mathrm{OH})_{2}, \mathrm{Zn}(\mathrm{OH})_{3}{ }^{-}$and $\mathrm{Zn}(\mathrm{OH})^{2-}{ }_{4}$. In fact, in the $\mathrm{pH}$ range 6.6-7.2, there is an equilibrium between $\mathrm{Zn}^{2+}$ and $\mathrm{Zn}(\mathrm{OH})^{+}$species in the solution and the 
surface hydroxide. At $\mathrm{pH}>12$, there is an equilibrium between surface hydroxide and zincates ions $\mathrm{Zn}(\mathrm{OH})_{3}{ }^{-}$and $\mathrm{Zn}(\mathrm{OH})^{2-}{ }_{4}$. In the region $7.2<\mathrm{pH}<12$ all the different species could be in solution and could also be in equilibrium with the hydrated zinc oxide surface. To resume, when the zinc oxide powder is immersed in the water, the surface of the oxide particles is hydrolyzed because of the physically and chemically adsorbed polar water molecules and a layer of zinc hydroxides is formed. In our range of $\mathrm{pH}$, the surface hydroxides could be transformed into hydrated colloidal particles of $\mathrm{Zn}^{2+}, \mathrm{Zn}(\mathrm{OH})^{+}, \mathrm{Zn}(\mathrm{OH})_{2}$ and $\mathrm{Zn}(\mathrm{OH})_{3}{ }^{-}$depending of the $\mathrm{pH}$ value reached.

In the same way, the molecular structure of silane is a function of the $\mathrm{pH}$ of the solution and differences in the molecular structure of the silane agent may very well affect the reactivity of functional groups. The structure of usual silane in aqueous solution has been studied in various environments by Fourier transform infrared spectroscopy ${ }^{69-73}$. In the case of APTES and its analogues, the structure obtained from the solution at $\mathrm{pH}=2$ indicated that the amine group forms an amine salt $\left(\mathrm{NH}_{3}{ }^{+}\right)$, whereas at $\mathrm{pH}=12$ the amine group is essentially free of hydrogen bonding. Between these two values of $\mathrm{pH}$, equilibrium is present. Moreover for $\mathrm{pH}>3$, the silane group after hydrolysis appears to be negatively charged and also regarding the $\mathrm{pKa}$ of the $\mathrm{NH}_{3}$ group (10.3), we must consider the possible intramolecular association between $\mathrm{SO}^{-}$and $\mathrm{NH}_{3}{ }^{+}$, for $3<\mathrm{pH}<10.3$, with partial or total proton transfer between these two groups according to the $\mathrm{pH}$ value. In all case of $\mathrm{pH}$ ranges in water, amino silanes hydrolyze into silanol ( $\mathrm{SiOH}$ group) rapidly whereas the rate of the condensation reaction of the silanol into siloxane (Si-O-Si) appears very dependent of the $\mathrm{pH}$. Sanchez et $a l^{74}$ have shown that at acidic $\mathrm{pH}$, the hydrolysis process of silane is essentially activated whereas for basic $\mathrm{pH}$ both hydrolysis and condensation are activated. Regarding our results and principally the chemical titration (Table 1) and specific surface area (Table 1) results, we can propose the following mechanisms: 
(i) at $\mathrm{pH} 6-8.5$, the zinc surface should be positively charged whilst the silanol group appears to be negatively charged and the amino group positively charged. Also, we can expect a fast and strong adhesion between the negative silanol and the positive surface of the zinc oxide. But the final amount of grafted silane is controlled by the fact that small condensation of the silanol into siloxane is expected (1) because condensation is not completely activated by $\mathrm{pH}<$ 9 and (2) due to the intramolecular association between $\mathrm{SiO}^{-}$and $\mathrm{NH}_{3}{ }^{+}$, most of APTES remain in solution as monomer. After a grafting of a few layers of Si-O-Si, the non-reacted silane is eliminated by washing and centrifuging the solution. In this case, the grafting should be very fast and is controlled by the condensation process.

(ii) at $\mathrm{pH} \approx 10.5$, the hydrolysis of silane into silanol and the condensation into siloxane (Si-O$\mathrm{Si}$ ) polymer is activated. Also, we can expect that silanol is condensed into siloxane but not preferentially onto the surface of zinc oxide, because it is not positively charged. However, high condensation is observed by the strong values of weight percentage of silicon $(\sim 5 \%)$ obtained by the chemical titration, the decrease of the value of the specific surface area for the basic process before heating and the presence of the $\mathrm{Zn}_{2} \mathrm{SiO}_{4}$ impurity after heating. In this case, the starting concentration of silane appears to be a very important parameter in the control of the grafting. Indeed for these concentrations aminosilanetriols form aggregates which later absorb on the $\mathrm{ZnO}$ surface.

(iii) In the toluene case condition, the percentage of silicon observed $(\sim 0.3 \%)$ by chemical titration could be explained by (i) the low water quantity present during the experiment, (ii) the hard aggregation of $\mathrm{ZnO}$ nanoparticles in toluene medium. In the toluene process, although siloxane bonds with the surface of silica may be formed in the absence of water ${ }^{65}$ (only in the case of aminosilane), the majority of water is chemisorbed and physisorbed on the surface of zinc oxide, such that the hydrolysis of the aminosilane and the condensation of the 
silanol are now only possible on the zinc oxide surface. In the condensation reaction this is due to the catalytic effect of the amino group.

\subsection{Diffuse reflectance properties}

The UV-Vis transmittance spectrum of non-grafted zinc oxide and grafted zinc oxide is represented in Figure 14. One can notice that the grafting process did not modify drastically the transmittance spectra of $\mathrm{ZnO}$. Non-grafted and grafted zinc oxide showed excellent UV-Shielding capacity and transparency in the visible light. Moreover, the preliminary results of photocatalytic decomposition of acetaldehyde have shown that the aminosilane coating could increases photostability (results not published). For sunscreen materials, it is known to this art that light radiation of wavelengths from $280 \mathrm{~nm}$ to $400 \mathrm{~nm}$ promote burning of the human epidermis. Also, we think that aminosilane-grafted zinc oxide ultrafine particles could play an important role as UV sunblock. ZnO silane coating could be used in order to obtain homogeneous dispersion of photostable nanoparticles and functionalized devices for ultrafine inorganic oxide containing sunscreen formulations. The $\mathrm{NH}_{2}$ group could be used as a reactive function capable of chemisorbing macromolecules or increasing the surface charge of particulate in order to obtain suspensions without the formation of hard agglomerates.

\section{Conclusion}

This paper describes the preparation of coated-zinc oxide nanoparticles (APTES$\mathrm{ZnO}$ ). The effects of coating conditions (acidic, basic and toluene) on the grafting, the structural and optical properties of these nanoparticles were studied.

1. In the three cases after grafting and annealing at $800^{\circ} \mathrm{C}$ for 8 hours in air, the crystallite size is remaining almost unchanged compared to the primary crystallite size. It is clear that the APTES coating plays a role of growth inhibitor even at $800^{\circ} \mathrm{C}$. This is 
confirmed both from XRD and SEM studies. This process could be used for the controlled synthesis of advanced ceramics.

2. In the three cases, it was possible to control the coating. In the acid process, the grafting seems to be very fast and is controlled by the condensation process. In basic process, the starting concentration of silane appears to be a very important parameter in the control of the silica contents and the grafting. In the toluene process, the grafting seems to be mainly controlled by the amount of the water on the $\mathrm{ZnO}$ nanoparticle surface.

3. From diffuse reflectance measurements, one can notice that the grafting process did not modify the transmittance spectra of $\mathrm{ZnO}$. Moreover, the preliminary results of photocatalytic decomposition of acetaldehyde have shown that the aminosilane coating increases the photostability. According to this results it seems that for a UVA/UVB sun block agent application, it would be desirable to produce silane-coated zinc oxide.

\section{Acknowledgements}

The authors thank N. Pontais, N. Labhsetwar, S. Takenouchi and T. Wada for great technical assistance. This work was funded by the Japan Science and Technology Corporation and under the Science and Technology Agency-Centre National de la Recherche (STACNRS) exchange program.

[1] Portier, J., Campet, G., Salardenne, J., \& Marcel, C. C. R. Acad. Sci. Paris 322 (1996) 343

[2] Mochinaga, R., Yamasaki, T. \& Arakawa, T. Sensor and Actuators B 52 (1998) 96

[3] Nahm, C.W. \& Park, C. H. J. Mater. Sci. 35 (2000) 3037

[4] Gal, D., Hodes, G., Lincot, D. \& Schock, H. Thin Solid Films 361-362 (2000) 79

[5] Lincot, D. Actualité Chimique (1999) 23 
[6] Pauporte, T. \& Lincot, D. Electrochem. Acta 45 (2000) 3345

[7] Pineda, M., Palacios, J., Alonso, L., Garcia, E. \& Moliner, R. Fuel 79 (2000) 885

[8] Turkoglu, M. \& Yener, S. Int. J. Cosmet. Sci. 19 (1997) 193

[9] Mitchnick, M., Fairhurst, D. \& Pinnell, S. J. Am. Acad. Dermatol. 40 (1999) 85

[10] Iwasaki, T., Satoh, M., Masuda, T., \& Fujita, T. J. Mater. Sci. 35 (2000) 4025

[11] Zu, P., Tang, Z., Wong, G., Kawasaki, M., Ohtomo, A., Koinuma, H., \& Segawa, Y. Solid State Commun. 103 (1997) 459

[12] Lindroos, S. \& Leskela, M. Int. J. Inorg. Mater. 2 (2000) 197

[13] Chen, Y., Bagnall, D., \& Yao, T. Mater. Sci. Eng. B75 (2000) 190

[14] Radulovic, P., Feigerle, C., \& Overbury, S. J. Phys .Chem. B 104 (2000) 3028

[15] Kaiya, K., Omichi, K., Takahashi, N., Nakamura, T., Okamoyo, S., \& Yamamoto, H. J. Mater. Chem. 10 (2000) 969

[16] Peulon, S. \& Lincot, D. J. Electrochem. Soc. 145 (1998) 864

[17] Jin, B., Im, S., \& Lee, S. Thin Solid Films 366 (2000) 107

[18] Zhu, S., Su, C., Lehoczky, S., George, M., \& Lowndes, D. J. Mater. Res. 15 (2000) 1125

[19] Sagaloicz, L. \& Fox, G. J. Mater. Res. 14 (1999) 1876

[20] Wong, E. \& Searson, P. Appl. Phys. Lett. 74 (1999) 2939

[21] Tsurumi, T., Nishizawa, S., Ohashi, N., \& Ohgaki, T. Jpn. J. Appl. Phys. 38 (1999) 3682

[22] Ryu, Y., Zhu, S., Budai, J., Chandrasekhar, H., Miceli, P., \& White, H. J. Appl. Phys. 88 (2000) 201

[23] Ryu, Y., Zhu, S., Look, D., Wrobel, J., Jeong, H., \& White, H. J. Crystal Growth 216 (2000) 330

[24] Ryu, Y., Zhu, S., Wrobel, J., Jeong, H., Miceli, P., \& White, H. J. Crystal Growth 216 (2000) 326

[25] Hiramatsu, M., Imaeda, K., Horio, N., \& Nawata, M. J. Vac. Sci. Tecnol. A 16 (1998) 669

[26] Minegishi, K., Koiwai, Y., Kikuchi, Y., Yano, K., Kasuga, M., \& Shimizu, A. Jpn. J. Appl. Phys. 36 (1997) L1453

[27] Isaki, M. \& Katayama, J. J. Electrochem. Soc. 147 (2000) 210 
[28] Maki, H., Ichinose, N., Ohashi, N., Haneda, H., \& Tanaka, J. Surf. Sci. 457 (2000) 377

[29] Butkhuzi, T., Chelidze, T., \& Georgobiani, A. Phys. Rev. B 58 (1998) 10692

[30] Ohnishi, T., Ohtomo, A., Kawasaki, M., Takahashi, K., Yoshimoto, M., \& Koinuma, H. Appl. Phys. Lett. 72 (1998) 824

[31] Yamaya, K., Yamaki, Y., Nakanishi, H., \& Chichibu, S. Appl. Phys. Lett. 72 (1998) 235

[32] Bagnall, D., Chen, Y., Zhu, Z., \& Yao, T. Appl. Phys. Lett. 70 (1997) 2230

[33] Ohashi, N., Sekiguchi, T., Aoyama, K., Ohgaki, T., Terada, Y., Sakaguchi \& T., Haneda, H. J. Appl. Phys. 91(6) (2002) 3658

[34] Reynolds, D., Look, D., \& Jogai, B. Solid State Commun. 99 (1996) 873

[35] Fukumura, T., Jin, Z., Ohtomo, A., Koinuma, H., \& Kawasaki, M. Appl. Phys. Lett. 75 (1999) 3366

[36] Kovtyukhova, N., Gorchinskiy, A., \& Waraksa, D. Mater. Sci. Eng. B69-70 (2000) 424

[37] Harada, Y., Kondo, H., Ichimura, N., \& Hashimoto, S. J. Lumin. 87-89 (2000) 405

[38] VanDijken, A., Meulenkamp, E., Vanmaekelbergh, D., \& Meijerink, A. J. Lumin. $87-89$ (2000) 454

[39]. VanDijken, A., Meulenkamp, E., Vanmaekelbergh, D., \& Meijerink, A. J. Phys. Chem. B 104 (2000) 4355

[40] VanDijken, A., Meulenkamp, E., Vanmaekelbergh, D., \& Meijerink, A. J. Phys. Chem. B 104 (2000) 1715

[41] Shi, G., Mo, C., Cai, W., \& Zhang, L. Solid State Commun. 115 (2000) 253

[42] Spanhel, L. \& Anderson, M. J. Am. Chem. Soc. 113 (1991) 2826

[43] Bahnemann, D., Kormann, C., \& Hoffmann, M. J. Phys. Chem. 91 (1987) 3789

[44] Saito, N., Haneda, H., Sekiguchi, T., Ohashi, N., Sakaguchi, I., and Koumoto, K. Adv Mater. Chem. 14(6) (2002) 418

[45] Wang, R.Y., Wu, X. C., Zou, B. S., Wang, L., \& Xu, J. R. Mater. Sci. Eng. (1998) 56

[46] Monticone, S., Tufeu, R., \& Kanaev, A. J. Phys. Chem. B 102 (1998) 2854

[47] Ya, K., Yin, H., De, T., \& Jing, T. Mater. Res. Bull. 33 (1998) 1703

[48] Lee, J., Hwang, J., Mashek, J., Mason, T., Miller, A., \& Siegel, R. J. Mater. Res. 10 (1995) 2295 
[49] Asokan, T. Mater. Res. Bull. 28 (1994) 1277

[50] Hingorani, S., Shah, D., \& Multani, M. J. Mater. Res. 10 (1995) 461

[51] Luo, J., Wang, H., \& Chiang, Y. J. Am. Ceram. Soc. 82 (1999) 916

[52] Hingorani, S., Pillai, V., Kumar, P., Multani, M., \& Shah, D. Mater. Res. Bull. 28 (1993) 1303

[53] Jose, J. \& Abdul Khabar, M. Mater. Sci. Eng. A304-306 (2001) 810

[54] Yabe, S. \& Momose, S. J. Soc. Chem. Jpn. 32 (1998) 372

[55] Jarvine, M, J. appl. Cryst. 26 (1993) 527

[56] Rodriguez-Carvajal, J. Commission on Powder Diffraction, Newsletter n²6, (2001) 12

[57] Audebrand, N., Auffrédic, J.P. \& Louër, D., Chem. Mater. 10 (1998) 2450

[58] Buining, P., Humbel, B., Philipse, A. P., \& Verkleij, A. Langmuir 13 (1997) 3921

[59] Abel, M., Watts, J. F., \& Digby, R. Int. J. Adhesion and Adhesives 18 (1998) 179

[60] Turner, M., Duguet, E., \& Labrugere, C. Surf. Interface Anal. 25 (1997) 917

[61] Perruchot, C., Chehimi, M., Delamar, M., Lacaze, P., Eccles, J., Steele, T., \& Mair, C. Synth. Met. 102 (2000) 1194

[62] Goodwin, J., Harbron, R., \& Reynolds, P. Colloid Polymer Sci. 268 (1990) 766

[63] Mendelovici, E., Frost, R., \& Kloprogge, J. J. Colloid. Interface Sci. 238 (2001) 273

[64] Heiney, P., Gruneberg, K., \& Fang, J. Langmuir 16 (2000) 2651

[65] Vrancken, K.C., Possemiers, K., Van Der Voort, P. and Vansant, E.F. Colloid. Surf. A 98 (1995) 235

[66] Saito, N., Haneda, H., Seo, W., \& Koumoto, K. Langmuir 17 (2001) 1461

[67] Jolivet, J. De la solution à l'oxyde, InterEdition and CNRS Edition 1994.

[68] Degen, A. \& Kosec, M. J. Eur. Ceram. Soc. 20 (2000) 667

[69] Ishida, H. \& Koenig, J. J. Colloid. Interface Sci. 64 (1978) 555

[70] Ishida, H. \& Koenig, J. J. Colloid. Interface Sci. 64 (1978) 565

[71] Chiang, C., Ishida, H., \& Koenig, J. J. Colloid. Interface Sci. 74 (1980) 396 
[72] Ishida, H., Chiang, C., \& Koenig, J. Polymer 23 (1982) 257

[73] Ishida, H., Naviroj, S., Tripathy, S., Fitzgerald, J., \& Koenig, J. J. Polym. Sci.:Polym. Phys. 20 (1982) 701

[74] Sanchez, C. \& Ribot, F. New J. Chem. 18 (1994) 1007 
Figure caption

Fig 1 XRD patterns of non-grafted zinc oxide powder before (A) and after (B) annealing at $800^{\circ} \mathrm{C}$ in air for 8 hours.

Fig 2 XRD patterns of grafted zinc oxide (acidic condition) powder before (A) and after (B) annealing at $800^{\circ} \mathrm{C}$ in air for 8 hours.

Fig 3 XRD patterns of grafted zinc oxide (basic condition) powder before (A) and after (B) annealing at $800^{\circ} \mathrm{C}$ in air for 8 hours.

Fig 4 XRD patterns of grafted zinc oxide (Toluene condition) powder before (A) and after (B) annealing at $800^{\circ} \mathrm{C}$ in air for 8 hours.

Fig 5 XRD patterns of non-grafted zinc oxide ( $\mathrm{ZnO})$ and yttrium oxide (Y2O3) powders.

Fig 6 Observed (dots), calculated (full line) and difference X-ray powder diffraction profiles of zinc oxide before grafting and annealing.

Fig 7 Observed (dots), calculated (full line) and difference X-ray powder diffraction profiles of zinc oxide before grafting and after annealing at $800^{\circ} \mathrm{C}$ in air for 8 hours.

Fig 8 Observed (dots), calculated (full line) and difference X-ray powder diffraction profiles of zinc oxide after grafting (Acidic process) and annealing at $800^{\circ} \mathrm{C}$ in ait for 8 hours.

Fig 9 Observed (dots), calculated (full line) and difference X-ray powder diffraction profiles of zinc oxide after grafting (Basic process) and annealing at $800^{\circ} \mathrm{C}$ in ait for 8 hours.

Fig 10 Observed (dots), calculated (full line) and difference X-ray powder diffraction profiles of zinc oxide after grafting (Toluene process) and annealing at $800^{\circ} \mathrm{C}$ in ait for 8 hours.

Fig 11 Representation of the apparent size calculated from the anisotropic size broadening written as a linear combination of spherical harmonics. (A) projection along [110], (B) projection along [101]) 
Fig 12 TEM images of non grafting and non-annealing zinc oxide nanoparticles.

Fig 13 SEM images of the non-grafted before (A) and after (B) heated at $800^{\circ} \mathrm{C}$ (in air for 8 hours). SEM images of the grafted zinc oxide before (C (acidic process)) and after (D (acidic process), E (basic process) and $\mathrm{F}$ (toluene process)) heated at $800^{\circ} \mathrm{C}$ (in air for 8 hours). The bar corresponds to $300 \mathrm{~nm}$.

Fig 14 Optical transmittance of the non-grafted and the grafted zinc oxide powder.

Table caption

Table 1 Apparent size (in $\AA$ ) non-grafted (before annealing) and grafted (after annealing) zinc oxide powders.

Table 2 Physical and chemical properties of non-grafted and grafted zinc oxide powders. 